\title{
Research on Sustainable Development and green and low- carbon clothing design
}

\author{
Dong Fanglin \\ College of Textiles and Clothing, Shanghai University of Engineering Sciences, Shanghai, China
}

\begin{abstract}
With the rapid development of the world economy, science and technology, more and more people are realizing that the serious situation caused by the environmental crisis affects people's lives. In the new era, people's awareness of green and low-carbon has been continuously raised, especially the daily use of clothing as a way of life and the flooding of new and old clothes, green and low-carbon concept of clothing design has become the trend of sustainable development in the future, around the sustainable development, green and low-carbon concept of clothing design and integration for the clothing industry to do a stable innovative development direction.
\end{abstract}

\section{Introduction}

Under the background of the early ancient times, the research found that people already have the green and low-carbon environmental consciousness, which imperceptibly influences the continuation and development of the future developed economy and science and technology, the main fabric of early people's clothing to animal fur, natural things: linen, wool, silk, bark and other fabrics made of clothing. With the continuous improvement of modern people's quality of life, people's awareness of green and low-carbon has become more and more intense. People live in harmony with nature. The awareness of green, low-carbon and environmental protection has become a mainstream trend in contemporary society, however, people neglect the transfer of clothes from closets to landfills and incinerators, and the world is facing the direction of old clothes shelving, slowly becoming a mainstream issue, green, low-carbon, recycled, re-used waste extraction material, the garment field of recycled fabric has attracted wide attention. The integration of green and low-carbon Clothing Sustainable Development Research, fully let people live in harmony with the natural environment, and clothing design products are inextricably linked.

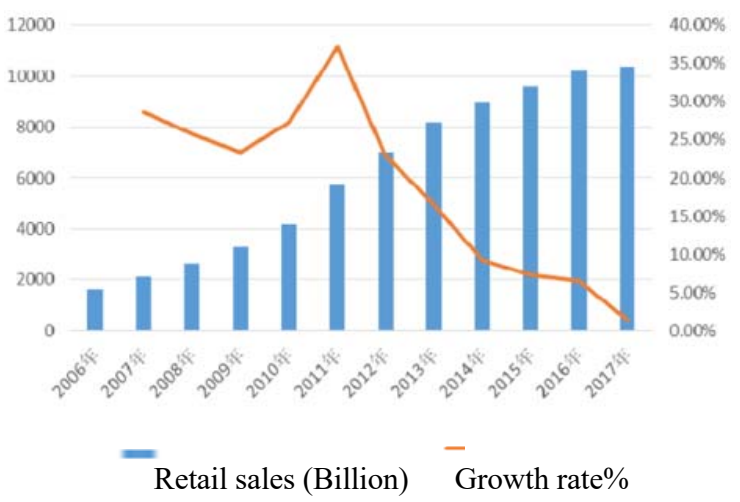

Figure 1. The recovery rate of textile products

\subsection{Trends in sustainable clothing}

In China's traditional garment manufacturing industry, cotton, linen, are commonly used materials, such materials in the traditional garment manufacturing process is difficult to be recovered and recycled. Because of the characteristics of its mode of production and clothing products, people are more and more aware of the problem of green and low carbon environment, and keep the clothing industry in line with the transformation form of green and low carbon, the importance of green and low-carbon fashion design, culture, science and technology and other factors complement each other. It has a deep influence on the research of green and low-carbon fashion design.

The whole life of green eco-low-carbon clothing from production to consumption hasn't caused pollution to the ecological environment and harm to human body, providing people with health, comfort and fashion to use while also saving natural resources to the greatest extent, guarding the home, to achieve the goal of harmonious coexistence between man and nature, to promote the clothing of the green ecological low-carbon. Compared 
with the traditional fashion design, the green eco-lowcarbon fashion design uses the recycling of used materials to design, in line with the current and future direction, can effectively ensure the practicality of clothing and green low-carbon; Advocated the idea of resource conservation. To solve the low-carbon environment to create a new green design methods and ideas.

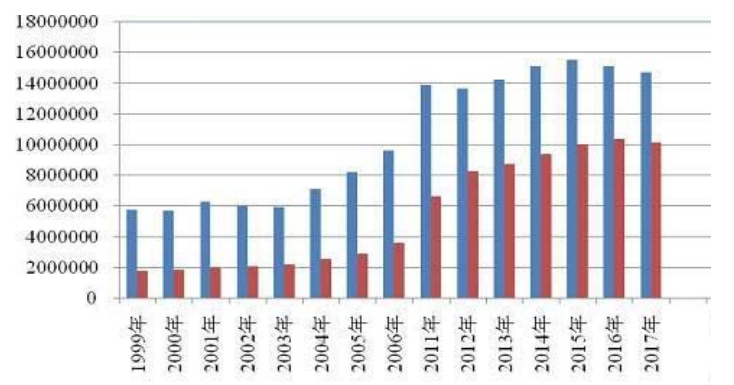

Chian1990-2017Textiles over the years Cumulative finished products (Ten thousand yuan)

- Chian1999-2017Cumulative finished garments over the years (ten thousand yuan)

Figure2.Cumulative finished products of textiles and clothing in 1999-2017

\subsection{Purpose and characteristics of green low- carbon clothing}

Green low-carbon environmental protection clothing design to a certain extent in line with the design of green, low-carbon, safety, health, comfort. Now the global trend of green and low-carbon fashion design is unstoppable. All countries in the world are warming up to study the green and low-carbon fashion design to restrict the market circulation and consumption of nongreen and low-carbon products, study the standard of Overall Comfort, health and harmlessness of environment.

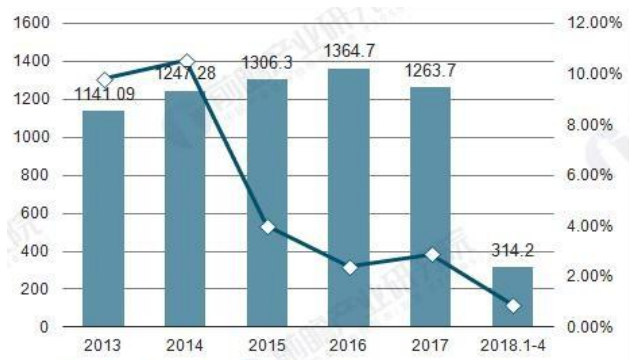

-- Total profit of textile and garment enterprises above De signated Size:Billion

- Year-on-year growth

Figure 3 Profit chart of textile and garment enterprises

When the Green low-carbon clothing design carries on the product development, first introduces the lowcarbon idea and with the traditional design factor overall consideration balanced ecology need as well as the profit space, grasp the factors such as green and lowcarbon-based, investment, product performance and other aspects. Secondly, on the premise of being able to guarantee the profit space, on the premise of being able to effectively ensure the maximum profit growth space of the enterprise, on the premise of being able to effectively ensure the safety and health of the enterprise's products and the green and low-carbon character, to avoid the ecological imbalance caused by negative effects. Again, the product isn't the low-carbon factor external reflection, internal and external factors from a variety of expectations, otherwise it is difficult to occupy a favorable market, it is difficult to play out the green low-carbon factors.

\section{The embodiment of sustainable development fashion design}

\subsection{Current market situation of sustainable fashion}

\subsubsection{Current situation of sustainable development of apparel in China.}

The rate at which people change clothes in our country is increasing. In the case of most people do not want to buy second-hand clothing, there is no reasonable and disposal of used clothing is growing every year. Direct disposal, on-the-spot burial and burning of open fire garbage will cause serious environmental pollution to the natural environment, ecology and water resources. It is conceivable that such a large number of old clothes will bring about environmental pressure. At present, green and low-carbon sustainable development is the direction of national and even global development.

Li Ning, a leading domestic sportswear company that has been responding to low carbon fashion earlier this year, has formed a partnership with empire. He invented ECO circle, ECO durable fabrics, and launched a recycling program for used clothing. Li Ning's stores recycle used clothing before sending it to the Teijin polyester fiber group, based in Tokyo, Japan, China, where it is broken down by natural chemicals and converted into natural polyester fibers, developed and manufactured from recycled materials for the production of new green sustainable recycling products; September 20,2009, during the special meeting on the research of low-carbon Environmental Protection Clothing, which was jointly conducted by the Environmental Protection Research Institute, the Goodall Center for Environmental Knowledge and culture in Jurchen people, Li Ning Company and Teijin fiber group, Teijin was the only one who gave the idea of "clothes ring" design in a constructive way, advocates that people should adhere to the green low-carbon environmental protection.

Puma has launched a free-of-charge recycling program for used sportswear in Shanghai and Beijing, and $\mathrm{H} \& \mathrm{M}$, which has announced the launch of a yearround recycling program for used clothing, has adopted a similar traditional approach to Puma's. H \& M and S \& Puma have both chosen I: Co as strategic partners. 
Some large-scale garment and textile industry is also helpful to systematize and standardize the pollution control after treating the most advanced garment and textile pollution equipment

In order to fully facilitate more citizens to recycle and dispose of used clothes by themselves in first-and second-tier cities, starting from May 2010, a city-wide pilot scheme was launched in Shanghai to recycle used clothes by sorting them, bringing them into residential communities like used clothes collection bins, and through the used clothes collection bins, the collection and disposal of used clothes is carried out by specialized companies of used clothes, and many urban areas have adopted the method of classified management and recycling of used clothes.

Taiwan's clothing brand SCAFE, introduced a lower carbon environmental protection clothing manufacturing process. They have reached agreements with some coffee retailers to recycle coffee grounds, paper cups and other coffee "waste" into trousers, shirts and suits that not only look the same as ordinary clothes, the utility model has the functions of coffee odor diffusion control, ultraviolet radiation protection, quickfreezing drying and other protection functions.

Based on a series of mature application cases in China, many green, natural and low-carbon fabric concepts have been used at different technical levels, such as green, natural and low-carbon fabric, primary energy recycling and "year ring of clothing", especially in the use of natural low-carbon raw materials and renewable resources of low-carbon cloth technology has in-depth study. Some key areas of China's national research working group for the Biodegradable plastic have further research findings, breakthrough currently facing the major issue of green environmental protection and low carbon. The domestic clothing brand speeds up the regeneration, the second use, provides the transformation low carbon green clothing design unceasingly.

\subsubsection{Status quo of su stainable de velopment of apparel abroad.}

Green low-carbon awareness of foreign countries are also very concerned about the development of the foreign used clothes market, the awareness of old clothes transformation is also used by many foreign design.

Jake Danaher, New York, USA. The "plastic cloth" is popular with many environmentalism. The products in the shop use garbage to turn into treasure. A large number of disposable plastic bottles are processed in a series to make swimsuits, changing the fashion world's linear use of re-materials to a system that has a circulation of goods is also what green low-carbon clothing design would like to see.

MIYAKE's clothes focus on simple science and technology, he runs through the concept of Oriental plane composition in three-dimensional cutting methods, reduce artificial traces, keep comfort and versatility, walking in a green and low-carbon fashion. More attention is paid to the harmony between man and nature.

Countries such as the United States and Japan, which are the main examples, are all gradually promoting green, low-carbon environmental protection and regeneration. The transformation model of the circular economy is gradually speeding up. Due to the increasing shelving of household clothes and garbage, the threat to the environment and ecology is becoming greater and greater, the imbalance between man and nature. In order to get rid of "make-then-use-and-throw-away" , the fashion pattern needs to be updated, so that the major clothing brands to create a green and low-carbon fashion design trend mainstream wave sustainable progress.

\section{3 design strategies for sustainable development}

\subsection{Research on sustainable design}

\subsubsection{Sustainable design materials.}

Material is one of the basic elements of clothing, and the progress of science and technology also provides us with the sustainable development design concept. The green clothing low-carbon and environmental protection clothing design provides a new type of using material, the fabric of the clothing design transformation method twice, that is to take all or part of the original low-carbon clothing for reorganization, transformation of a brandnew clothing design style, the old clothes through disassembly, reorganization and transformation into both fashionable and personalized clothing, to create and design new and more environmentally friendly lowcarbon clothing. Designers can also use their own expertise to transform the material to take on a variety of styles of appearance.

In the development and utilization of fabric recycling flow pattern, common fabrics are cotton, hemp, silk, wool, chemical fiber materials, as well as synthetic materials and recycled materials. Low-carbon green fabric all over the world are developing new types of textiles, divided into natural fiber, renewable environmental protection fiber and biodegradable synthetic fiber class. Natural Green fabrics are also environmentally friendly and green is also an important embodiment of low-carbon environmental protection. This is also a continuous production line. This kind of fabric technology, which is refined by natural vegetable oil and pure manual process, although complicated, but it is very environmental protection, in the numerous international fashion show hall clothing, many are also the application of natural environmental protection fabric products. With the new type of pulp environmentfriendly cloth as raw material, in the surface coating mortar plays the role of wind and rain. The water-based fabric burying is usually convenient and can absorb water and decompose by itself, which reduces the pollution to the environment. With the rapid development of science and technology in the garment 
and fabric manufacturing industry in China, it's also believed that carbon fibers in dyed coffee can be obtained by directly using the charcoal residue of dyed coffee filtered at high temperature as the raw material for dyeing, the fabric has the functions of producing negative ions, bacteriostasis, Deodorization and antiultraviolet

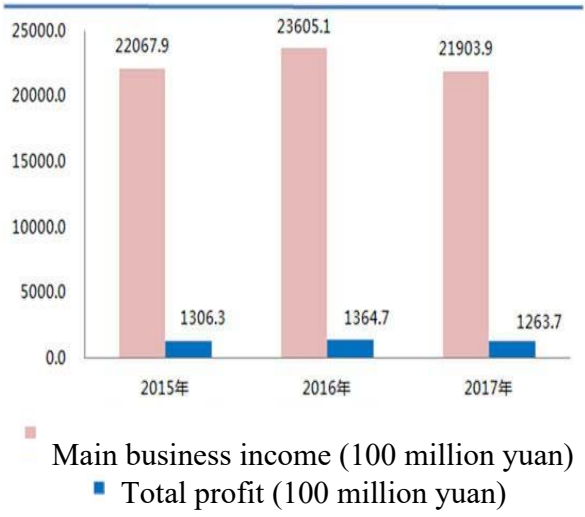

Figure 4 Profit chart of textile and clothing

For the secondary processing design of recycled fabric, the green and low-carbon clothing design is embodied through the design of addition and subtraction, deformation design and combination design. The design of adding, subtracting and sending is mainly based on the original foundation through traditional means such as embroidery, filling and decoration. The design of "old" and "regeneration" is also the direction of development combined with science and technology, and many of them are designed with the techniques of handicraft, recycling of the weaving process also reflects the green low-carbon clothing design, showing a different level of beauty, one of the performance of green low-carbon fabrics. Many brands are increasingly interested in recycled and alternative fabric.

\subsubsection{Sustainable color design.}

Sustainable Development type of clothing color is one of the indispensable, color is also the first visual perception of people, different color collocation and proportion give people different senses. For the Green low-carbon clothing, in the return to the natural ecological natural color similar to the visual organs of the people and Comfort. For the second design of color, the degree of color in the recycled old clothes is almost low, and then on the basis of the second processing, through the extraction of natural plant dyeing, tie-dye, Batik, pattern design to make the whole look brand-new. Therefore, the combination of the traditional way and technology means, blend with each other to better reflect the green low-carbon clothing design.

\subsubsection{Sustainable design.}

Green low-carbon clothing style design, the characteristics of human body structure, design simple and comfortable as well as functional and practical style clothing, completely green low-carbon clothing to do the foundation. In today's clothing styles mostly use three-dimensional cutting, the waste and consumption of fabrics also have an impact on the design of styles using plane cutting and three-dimensional cutting plus the use of a small number of fabrics, using diversified design, can use splicing, replacement, etc. , clothing parts such as sleeves, collars and pockets can be designed into a variety of combinations of old clothing fabric, different from the traditional clothing design, the pursuit of Natural Comfort Green low-carbon clothing and highlight personalized display.

\subsection{Sustainable development of clothing in China}

Green low-carbon clothing in the design, production, use of the entire life cycle should be achieved circular economic flow model, a new round of development model to update the circulation system, to promote rapid economic development, the brand effect follows the principle of "3R1D" which can reduce, repeat, recycle and degrade. For example, actively develop "zero waste" manual plate-making and worn-out clothing processing technology, use worn-out leftover materials method processing worn-out clothing or other accessories, will be worn-out leftover materials and worn-out processed clothing pre-processing classification, multi-cycle production mode of manufacturing.

\subsection{Sustainable and innovative application of modern technology in garment design}

China has a long history of using garment dyes for printing and dyeing, and it's difficult to understand the ways of printing and dyeing commonly used in the manufacture of dyes, fabrics and garments in cultural tradition, including China's traditional Dyes Batik, tiedye, weaving and other printing and dyeing materials used are considered to be natural low-carbon. Under the background of the high-tech era, people advocate the green and low-carbon clothing design in the clothing industry and society, pay attention to the regeneration and alternative cycle design, and design production process by hand, the secondary recycling of materials using green low carbon products reduces and avoids the secondary pollution damage to the environment produced by complex industrial processes and the excessive waste of resources, thus reducing carbon emissions, for the low-carbon Green clothing design provides innovation and new ideas forward.

\subsection{Development and collision between traditional culture and modern technology}

\subsubsection{Theories and methods of sustainable design.}

Design is like a person's life, with a cycle, the end of the cycle, the meaning of design also began to disappear. 
But the truly classic design can always withstand the test of time, unlimited extension and expansion of their own cycle. The wind direction of art and design is changing, so is the aesthetic of human beings. Works that are truly enduring have prolonged their existence indefinitely because their designs conform to the most basic aesthetic rules and the aesthetic laws of human beings, this is the enduring power of the rule. In the concept of sustainable design, it is necessary to fully apply the concept of design, many of the classic, long-lasting design works, even after many years have their infinite vitality, although we can not replicate such success, but we can deeply carry out such thought and theory in the design, through the reasonable design, creates one conforms to the present esthetic, has thousands of years vitality excellent design.

The promotion of the Green and low-carbon concept stimulates the development of various industries, renews and rotates the Global Model, promotes the design of low-carbon and green clothing, and also makes people aware of the innovation of the green and low-carbon concept, let the traditional pattern and technology combine to create a green and low-carbon clothing design, fully understand the sustainable development of green and low-carbon clothing, so that the whole becomes a more healthy, comfortable, pure and fashionable environment, let people really understand the concept of green low-carbon.

\subsubsection{Inherit ance and in novation of traditional culture in fashion art.}

In recent years, a new voice has appeared on the stage of the fashion industry. The Chinese traditional culture, represented by the Chinese style, is gradually entering the international fashion industry and forming the fashion of the Chinese style to a certain extent. Exploring the reasons for the rise, we can easily find that with the development of China's economy and social progress, people's spiritual needs are more prominent, and the accelerated development of the Internet has provided a vast space for the cultivation of personality, the richness of Chinese culture also provides ample space for discovering one's hobbies and cultivating one's own interests. In such a climate, many people who try to combine the traditional culture with the modern fashion art try to innovate and transform the traditional culture to form a cultural trend with more modern artistic characteristics and to form a more individual flavor, the elements of the traditional culture of fashion, in the information age, are amplified by the spread of the Internet and social media to deepen its identity on a larger scale.

The inheritance and innovation of traditional culture in fashion art means that the tolerance of cultural ideas should be further expanded. Attention should be paid to the development and prevalence of ancient customs in the role of youth. The combination of traditional culture and modern fashion is undoubtedly giving new vitality to the traditional culture and restoring its vitality and vitality in a modern way.

\subsubsection{Application of traditional handicraft in fashion.}

In the age-old project is gradually expanded, the decline of contemporary, there are always some old and pure skills, in the information age development of today by the flood submerged, we forget. But fortunately, there are more and more people around us to explore the ancient elements of China into their own design and ideas. The traditional handicraft is one of the important inspiration sources of contemporary design, the true non-abandoned handicraft emanates the natural, humanistic, natural beauty, and the characteristics it displays, advocated the idea is that we now people can not imagine the exquisite and ingenuity. A piece of nonabandoned handicraft embodies the hard work and wisdom of craftsmen. It shows US unique folk customs and contains the essence and strength of Chinese traditional culture. An artifact has stood the test of time and the vicissitudes of things for thousands of years.

In today's fashion world, the traditional hand-made embroidery on the runway often comes from the crossborder association between the hand-made inheritors and the designers, so that many non-heritage handicrafts can be brought back to life, and the works can be innovatively manufactured and put on the market platform, so as to promote the development and spread of ich.

\subsubsection{Sustainable and innovative app lication of modern technology in fashion art.}

To create better sustainable products, modern technology needs to be incorporated into the design. First of all, to incorporate readable content into the design, with good readable fonts, pictures are the foundation, design is the connotation, typography should be creative and innovative, no matter when, any device that looks at the content of a post should be attractive enough to be recognized by the user in any situation. Fancy Fonts designed to appeal to the reader can be eye catching in certain situations, but may not always be able to understand what they are trying to convey. In the design of visual communication, should be in place, the most important direct and clear expression to express the meaning of the message, the design of the text, pictures, text should be directly linked with precision, create a comprehensive sense of experience and reading sense. In the visual communication should also be applied to some interactive design, speaking of different elements interact together, users will have a combination of interaction with the sensory experience, small interaction details can make the design more authentic, give the project a different meaning. When designing interactive elements, the USABILITY and practicability of design have to be considered in the category of products. The interaction brought by more competitive works should be unique, interactivity should be unique and irreplaceable, used in visual communication to tell a story, act as a guide to the client, and delight the client with subtle effects. 


\section{Conclusion}

Green and low-carbon is an important trend in the future. The concepts of Chinese garment production and consumers are becoming more and more mature. They have a good grasp of the changing factors of people, nature, time and space background, industrial ecological environment, etc., make the clothing with Chinese characteristics green and low carbon industry. In recent years, more and more attention has been paid to the issue of environmental protection, through the green and lowcarbon ecological design, people's ecological civilization level has been continuously improved, and the research and application of clothing design have been brought into play to realize the sustainable development of green and low-carbon. In the design of green low-carbon clothing, not only consider "serving people", "people-oriented", zero waste fashion is equal to not make garbage fashion green low-carbon clothing brand, but also consider the balance of the environment. The key to the development of green and low-carbon clothing lies in ecological, natural, environmental protection, health and so on. With the development of the new era, the low-carbon Green clothing is gradually penetrating into people's life. The daily recycling pattern of clothing plays an important role in the clothing industry.

\section{References}

1. Zhou Jie. Discussion on the application of green design in Garment Design J. Western leather, 201714:99. 2.
2. Cao Yu, Zheng Qiyun. Study on the decision of recycling dual perishable products under stochastic market demand [ $\mathrm{J}$ ] . Journal of Anhui Normal University (humanities and Social Sciences Edition), 2016(6).

3. Meng Qiang, Li Fangyi, Li Ching, Zhou Lirong, Ji Qin. Rapid Life Cycle assessment method for scheme design based on Green FeaturesJ.Computer-integrated manufacturing, 21,20153:626-633.

4. Yao Weixin. Research on the mode of recycling and reuse of waste clothing based on enterprise-oriented -- taking as example J. International Textile Review, March 2014.

5. Guo Yan. Research on the concept, principle and hierarchical structure management of Zero Abandonment J. Textile reporting, October 2014(10).

6. Wang Chen. Research on the application of threedimensional modeling technique in Clothing Regeneration D. Zhejiang: Zhejiang Sci-Tech University, 2014.

7. Bai Yuling. The present situation and strategic choice of low-carbon Textile clothing in China J. Foreign Trade and economic practice, July 2012,(7).

8. Hao Shuli. RESEARCH ON LOW-CARBON PATTERN OF GARMENT INDUSTRY J. Shandong Textile Economy, 2011(08).

9. Zhu Yuansheng. Fabric and Costume Design M. SHANGHAI: China Textile University Press, 2008.11 